\title{
APPLYING ALPHA-BETA ALGORITHM IN A CHESS ENGINE
}

\author{
Werda Buana Putra dan Lukman Heryawan \\ Computer Science Department \\ Universitas Gadjah Mada \\ Email: magmaflood@gmail.com
}

\begin{abstract}
ABSTRAK
Algoritma Minimax dikenal sebagai solusi untuk mengurangi beban pencarian pada mesin catur. Namun, metode yang lebih dalam diperlukan untuk meningkatkan performa algoritma ini. Salah satu solusinya dikenal dengan algoritma Alpha-Beta Pruning. Idenya adalah dengan mengeliminasi cabang yang dianggap tidak diperlukan di dalam pohon pencarian.
\end{abstract}

Kata Kunci: Algoritma; Alpha-Beta Pruning; Mesin catur; Minimax; Pohon pencarian.

\section{ABSTRACT}

Minimax Algorithm, is a solution to reduce the burden on hardware in chess engine. However, a more in-depth method is needed to further increase the search algorithm. One of those solutions is called Alpha-Beta Pruning algorithm. The idea is to eliminate the unnecessary nodes in the search tree.

Keywords: Algorithm; Alpha-Beta Pruning; Chess engine; Minimax; Search Tree. 


\section{INTRODUCTION}

The origin of chess spans over 1500 years ago. The earliest predecessor of the game probably originated in India. From India, the game spread to Persia. When the Arabs conquered Persia, chess was taken up by the Muslim world and subsequently spread to Southern Europe. In Europe, chess evolved into roughly its current form in the 15th century.

\section{Chess}

Chess is one of the most well-known 2-player board game. Played on an $8 \times 8$ white and black squares. One player playing white pieces, while the other playing as black pieces

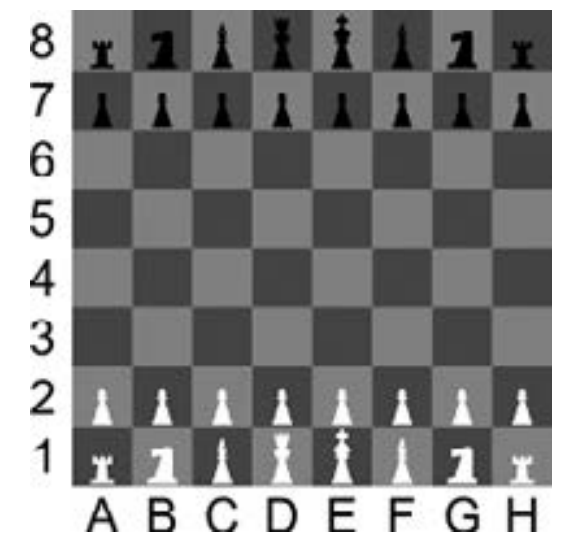

Figure 1.

Chess game Initiation

When the game starts, each player put the 16 of their chess pieces on the board in a specific order. These chess pieces will be moved to attack, defend, threat, and capture the other player's pieces. The difference in their characteristic is the main factor while constructing strategies in chess.

The aim of the game is to capture the opponent's 'King' piece. The game will end either when a king is captured or when the condition for stalemate has met. Stalemate refer to as draw, the condition for this are determined by FIDE, a World Chess Federation.

\section{Chess Pieces and Their Move Range}

Each player would be given 16 pieces, with 8 different role of pieces consisted of 8 pawns, 2 knights, 2 bishops, 2 rooks, a queen and a king with each role has their own unique move range. One thing in common is that the move path cannot be looped on the board. Meaning that when a piece has reached a certain corner of the chess board, they must stop and they have to go all the way back if they want to reach another side. Firstly, Pawn: Pawns are allowed to move 1 square forward toward enemy zone. On their first move, they are allowed to move 2 squares forward, however, they captures by moving 1 square diagonally forward. And should they be able to reach the last row of opponent's side, pawn can be promoted into any piece. Secondly, Rook: Rook are allowed to move straight as far as the board allows it. Thirdly, Bishop: Bishop are allowed to move diagonally in any range. Fourthly, Knight: Knight's move are different than any other pieces, they move in an "L" letter shape with total of 3 square move. Fively, Queen: The most powerful piece of all. Queen move range is the combination of bishop's and rook's move range. Sixthly, King: Similar to Queen, only that King can only move 1 square to it's neighbor squares.

\section{Setting Up the Board}

The fundamental of building a chess engine is the representation of the chess board which affecting on how the chess engine will track the board and observe the ruling. Our chess engine, which we will refer as "Harmonia", is designed as such so it would be able to interract with Arena, a GUI for open source chess engine. It is essential to properly understand what a chess engine required to be able to communicate with the GUI. However, we will skip this part and move to the design. Out of 24 parts which construct "Harmonia", we will talk about 3 of those which is essential. In file board.cpp, we will find out how the engine recognize, not only the whole board, but also all the pieces.

The chess board will be recognized with a representation of $8 \times 8$ matrices. The row will be coded from number 1 to 8 , and the column will be represented with letter ' $a$ ' to ' $h$ '. 
Int i,type,k=7;

char ch;

fprintf(fout," abcdefghln +--------- $\ln 8 \mid$ “);

Figure 2 .

Chessboard Initiation Code

The pieces will be represented with letter that symbolized it's role, it is convenient that $\mathrm{C}^{++}$is case sensitive, because this way, we will be able to identify the pieces for each side by giving them the same letter, if the pieces role is the same, yet the engine can differ them by using different letter case.

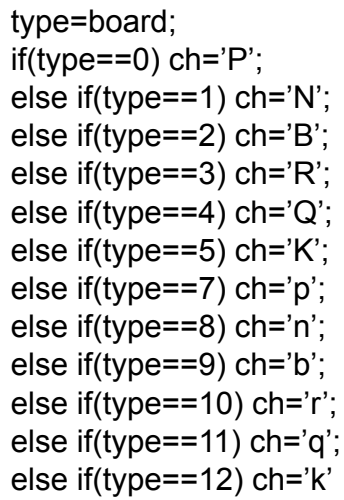

Figure 3.

Naming Chess Pieces

\section{RESULT AND DISCUSSION Basic Evaluation}

File Evaluation. h provide a sequence of how the chess pieces will get value depended on their position. These value, later on, will be used to run Harmonia.

\section{// Pawn scores White}

$\{0,0,0,0,0,0,0,0$

$20,26,26,28,28,26,26,20$,

$12,14,16,21,21,16,14,12$,

$8,10,12,18,18,12,10,8$,

$4,6,8,16,16,8,6,4$

2, 2, 4, 6, 6, 4, 2, 2,

$0,0,0,-4,-4,0,0,0$,

$0,0,0,0,0,0,0,0\}$,

Figure 4.

Pawn's Basic Value

Pawn's evaluation point is at It's peak just before the last square from it's opponent's side (ie : it would be $7^{\text {th }}$ row for white's pawn). They will get 0 point as they will get promoted immediately into another piece type.

\begin{tabular}{|c|}
\hline 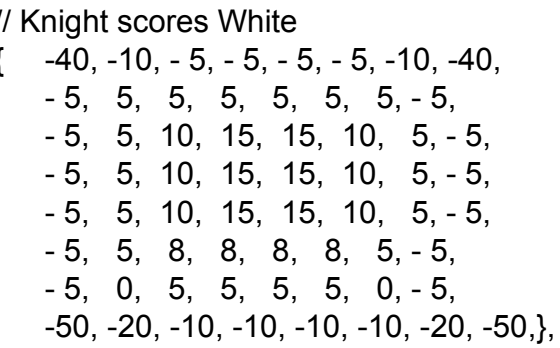 \\
\hline
\end{tabular}

Figure 5.

Knight's Basic Value

Knight is the only piece which can hop over another piece (s). This particular trait made them as the best support when played in middle field. However, due to it is limited move range, they are most vulnerable in corner side of the board.

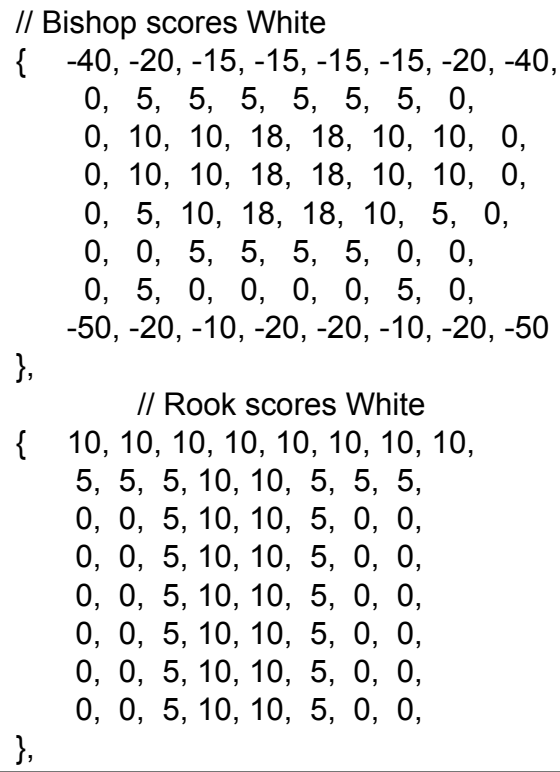

Figure 6.

Bishop and Rook's Basic Value

Even tough both rook and bishop has a wide move range, the proportion of their evaluation is very different. For rook's case, they still possess huge threat for opponent at the far end of the board. Unlike rook, bishop has many disadvantages while on the board's edge, either in friendly side or in the opponent's side. 
It's so because while in corner, bishop only have 1 way move range. This is the reason as to why most player value bishop at the same value as a knight.

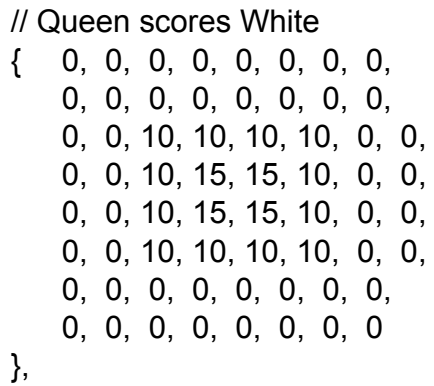

Figure 7.

Queen's Basic Value

Queen piece doesn't have a significantly different value while placed on any square. However, just like rook, queen doesn't have any square which would make them in a disadvantage, assuming there's no piece stand on their move range. But a queen have some square where they would get 15 point. This is considered as great value, assuming a queen is at the same time is mostly a main target as capturing a queen will at the same time chipping opponent's power in great value.

// King scores White

$\{0,0,0,0,0,0,0,0$,

$0,0,0,0,0,0,0,0$,

$0,0,0,0,0,0,0,0$,

$0,0,0,0,0,0,0,0$,

$12,8,4,0,0,4,8,12$,

$16,12,8,4,4,8,12,16$,

$24,20,16,12,12,16,20,24$,

$24,24,24,16,16,6,32,32\}$,

// King end-game scores White

$\{-30,-5,0,0,0,0,-5,-30$,

$-5,0,0,0,0,0,0,-5$,

$0,0,0,0,0,0,0,0$,

$0,0,0,5,5,0,0,0$,

$0,0,0,5,5,0,0,0$,

$0,0,0,0,0,0,0,0$,

$-10,0,0,0,0,0,0,-10$,

$-40,-10,-5,-5,-5,-5,-10,-40\}$

Figure 8.

King's Basic Value

King, logically, will have different purpose between the beginning of the game and toward the end of the game. While the game is near it's end, less pieces will be available, thus the king's struggle to survive is more depended on the position of itself rather than depending on piece's defense.

Despite all that, King still possess some threat. This is mainly because near the game's end the side at disadvantage will most likely reserve to a stalemate option. Which is easier to be done when the king have more squares to move.

\section{Applying Alpha -Beta Algorithm}

This is the main part of the engine. Search. cpp file will calculate and weighing whether a value is worthy to be evaluated using AlphaBeta algorithm. In this matter, we will make the engine operates differently to avoid overlapping.

Board $=\left({ }^{*}\right.$ GameBoard $)$;

MakeMove(\&vMoves[i]);

score=-Negamax (\&Board,iDepth+1,!liColor);

if(score $>$ bestscore) bestscore=score;

Figure 9

basic scoring

The algorithm that just shown, show us Minimax process of sorting inside the engine. Basically, Alpha-Beta pruning will cut unnecessary node which considered unworthy to be calculated further.

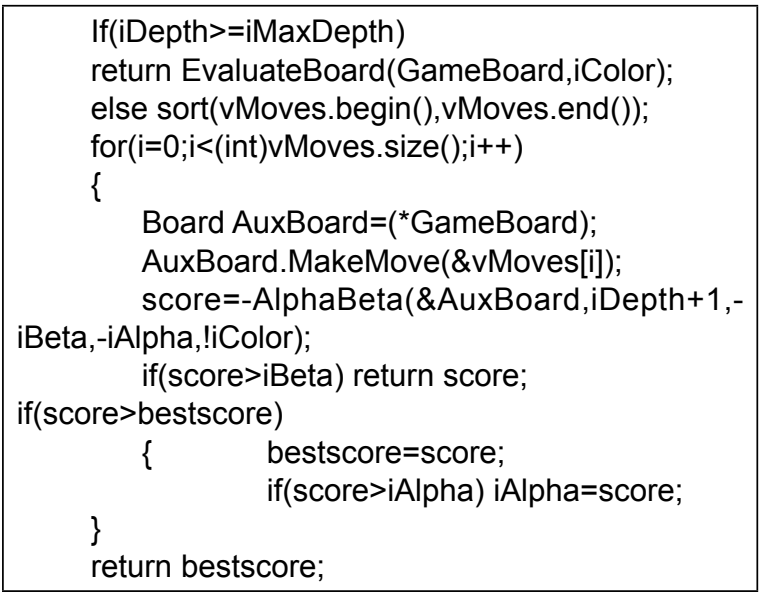

Figure 10.

Cut off's Logic 
Algorithm above briefly explain to us on how armonia chess engine will do it's pruning on unnecessary nodes.

\section{Testing}

The testing is done using Arena version 3.5, a GUI chess interface which commonly used in online match. The testing hardware use a dual-core Intel processor and 2GB RAM.

\section{1st match: Harmonia vs Houini $\mathbf{1 . 5}$}

Harmonia chess engine will be up against Houdini 1.5 on the first test. In the first match, Harmonia will play as white, and Houdini 1.5 will play as black.

Table 1. Opening of 1st Match

\begin{tabular}{l|l|l}
\hline No & White : Harmonia & \multicolumn{1}{|c}{ Black: Houdini } \\
\hline 1 & d 4 & Nf6 \\
\hline 2 & Nc3 & d5 \\
\hline 3 & Bf4 & e6 \\
\hline 4 & e3 & Bb4 \\
\hline 5 & Bd3 & c5 \\
\hline 6 & dxc5 & \\
\hline
\end{tabular}

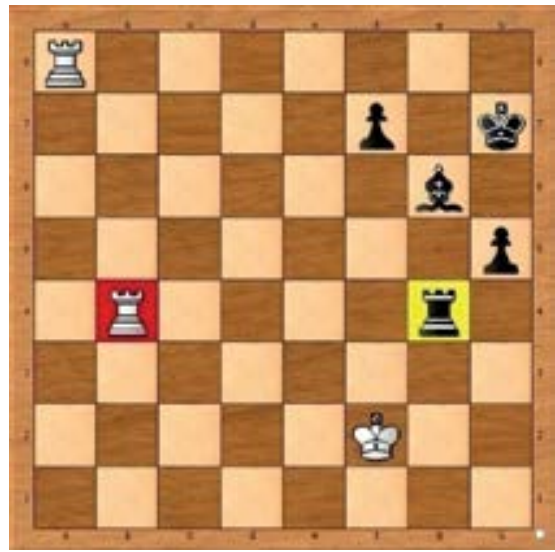

Figure 11.

Position on 1st match after 60 .... Rh7

After 60th move, Harmonia commit a 3 move repetition, hence the game was concluded with a stalemate.

\section{2nd Match: Harmonia vs Hermann}

In the 2 nd test, the out of 4 plays, none could be finished. In every play, either one of the engine would eventually crash.
Table 2. Opening of 2nd Match

\begin{tabular}{l|l}
\hline $\begin{array}{c}\text { White : Harmonia } \\
(\mathbf{1 7 5} \text { KB) }\end{array}$ & $\begin{array}{c}\text { Black : Hermann (497 } \\
\text { KB) }\end{array}$ \\
\hline $1 . \mathrm{Nc3}$ & $\mathrm{Nf6}$ \\
\hline $2 . \mathrm{d} 4$ & $\mathrm{~d} 5$ \\
\hline $3 . \mathrm{e} 4$ & \\
\hline
\end{tabular}

A bad move from Harmonia. Harmonia apparently wasting this pawn for no reason. Hermann evaluate this mistake and make no hesitation as an answer.

Table 3.

Mid-game of 2nd Match

\begin{tabular}{l|l}
$\begin{array}{c}\text { White : Harmonia (175 } \\
\text { KB) }\end{array}$ & $\begin{array}{c}\text { Black : Hermann (497 } \\
\text { KB) }\end{array}$ \\
\hline & Nxe4 \\
\hline Qh5+ & g6. \\
\hline
\end{tabular}

This is the second mistake from Harmonia, a check move without proper preparation.

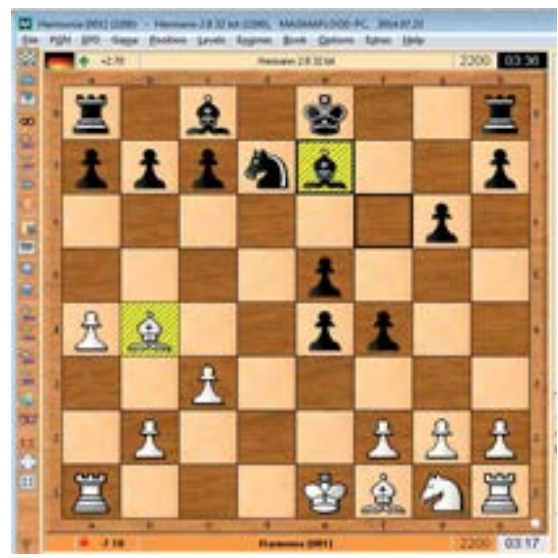

Figure 12.

Position on 2nd match after 14.Bb4 Be7

After some notable moves, Harmonia crashed itself in midway.

Table 4. End-game of 2nd Match

\begin{tabular}{l|l}
\hline $\begin{array}{c}\text { White : Harmonia (175 } \\
\text { KB) }\end{array}$ & $\begin{array}{c}\text { Black: Hermann (497 } \\
\text { KB) }\end{array}$ \\
\hline Bb5 & Bxb4 \\
\hline White crash & \\
\hline
\end{tabular}




\section{3rd Match: Harmonia vs AnMon}

In the last match, Harmonia will be faced with AnMon engine. AnMon is slightly different with the previous engine Harmonia had faced. AnMon using Nalimov database as a playbook and Quiescence algorithm as it's base.

Table 5. Opening of 3rd Match

\begin{tabular}{|l|l|l|}
\hline & \multicolumn{1}{|c|}{$\begin{array}{c}\text { White : Harmonia } \\
(\mathbf{1 7 5} \text { KB) }\end{array}$} & $\begin{array}{c}\text { Black : AnMon (215 } \\
\text { KB } \\
+ \text { Nalimov database } \\
\mathbf{1 , 2} \text { MB) }\end{array}$ \\
\hline 1 & e4 & c6 \\
\hline 2 & d4 & d5 \\
\hline
\end{tabular}

Engine with playbook will most likely playing some particular pattern in the early game, based on the database it has.

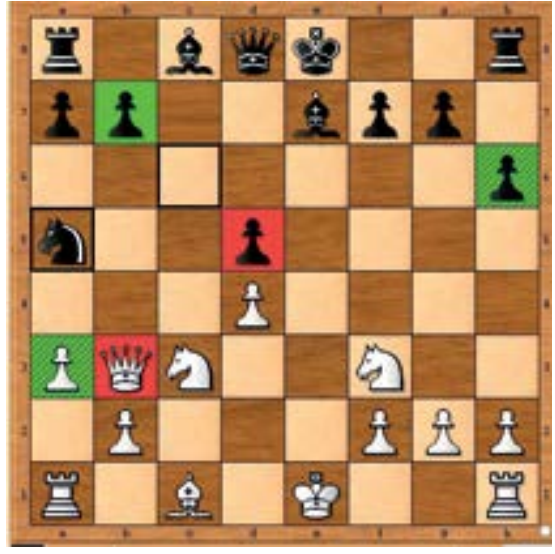

Figure 17.

Position on 3rd match after 12. Qb3 Na5

After 12th turn, harmonia and AnMon made a lot of exchange of it's pieces. The condition afterward is as follow.

Table 6. Mid-game of 3rd Match

\begin{tabular}{|l|l}
\hline $\begin{array}{c}\text { White : Harmonia (175 } \\
\text { KB) }\end{array}$ & $\begin{array}{c}\text { Black : AnMon } \\
\text { (215 KB+Nalimov } \\
\text { database 1,2 MB) }\end{array}$ \\
\hline Rf8 & Ke7 \\
\hline Rg8 & \\
\hline
\end{tabular}

Harmonia just wasting a turn by moving it's rook to g8, which supposed to be h8, so that would stop Black king's pursue over the rook.

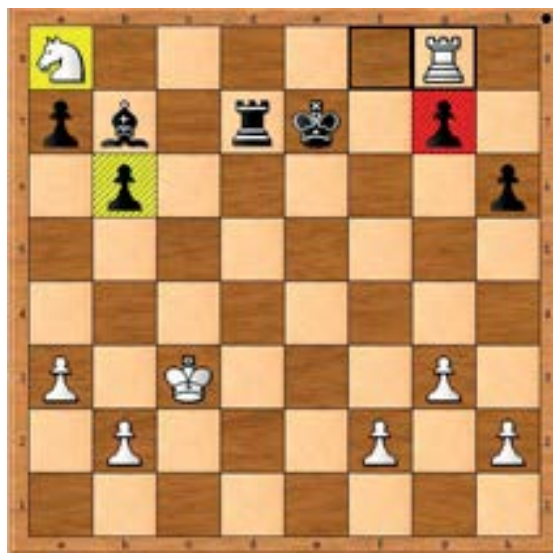

Figure 19.

Position on 3rd match after 29. Rg8

By this point, Harmonia commit a 3 move repetition which resulted on a stalemate.

\section{CONCLUSION}

Two out of 3 matches, Harmonia was able to give 2 stalemate results. On 1st and 3rd match, Harmonia was able to avoid losing the match despite some wrong move it has made.

Table 7. Resource Used in Each of Chess

Engine

\begin{tabular}{l|l|c|c}
\hline \multicolumn{1}{c|}{ Engine } & Avg \% CPU & Memory & \multicolumn{1}{c}{ Size } \\
\hline Harmonia & 51 & $110.824 \mathrm{~KB}$ & $175 \mathrm{~KB}$ \\
\hline Hermann & 52 & $138.888 \mathrm{~KB}$ & $497 \mathrm{~KB}$ \\
\hline Houdini & 55 & $140055 \mathrm{~KB}$ & $1,5 \mathrm{MB}$ \\
\hline Anmon & 54 & $134.444 \mathrm{~KB}$ & $1,4 \mathrm{MB}$ \\
\hline
\end{tabular}

From tha given data, it's clear that Harmonia using the least resource compared to another engine given above.

Harmonia's opponent in a match was deliberately chosen with the bigger size, which infer that the engine would have more option in it's calculation. The fact that Harmonia was able to give 2 stalemate out of 3 matches. This conclude that Alpha-Beta pruning algorithm is a solution to cover an engine's limitation with effective calculation. 


\section{BIBLIOGRAPHY}

Abdelbar, A.M., 2005, Alpha-Beta Pruning and Alth"ofer's Pathology-Free Negamax Algorithm, ICCA.

Dechter, R., 2010, Rapier: A Chess Engine.

Elo, A. E., Sloan, S., 2008, The Rating of Chess Players, Past and Present Paperback.

Eppstein, D., 1999, Finding the $k$ shortest paths, Dept. Information \& Computer Science, UC Irvine,

Festa, J., Davino, S., 2013, "IAgo Vs Othello": An artificial intelligence agent playing Reversi. ceur-ws.org/Vol1107, diakses 10 November 2014.

John, F.N. , 1950 Equilibrium Points in n-Person Games. Proc. Natl. Acad. Sci. USA .

Lin, Y. C. 2014, The Hierarchical Minimax Theorems, http://journal.taiwanmathsoc. org.tw, diakses 10 November 2014.

Raghavan, T.E.S., 1994, Handbook of Game Theory, Elsevier Science B.V., , 738.

Reinefield, A., 1983, An Improvement to The Scout Search Tree Algorithm, ICCA Journal. 